University of Wollongong

Research Online

Faculty of Engineering and Information

Faculty of Engineering and Information

Sciences - Papers: Part B

Sciences

2018

Thermal perceptions, preferences and adaptive behaviours of occupants of nursing homes

Federico Tartarini

University of Wollongong, federico@uow.edu.au

Paul Cooper

University of Wollongong, pcooper@uow.edu.au

Richard Fleming

University of Wollongong, rfleming@uow.edu.au

Follow this and additional works at: https://ro.uow.edu.au/eispapers1

Part of the Engineering Commons, and the Science and Technology Studies Commons

Research Online is the open access institutional repository for the University of Wollongong. For further information contact the UOW Library: research-pubs@uow.edu.au 


\title{
Thermal perceptions, preferences and adaptive behaviours of occupants of nursing homes
}

\begin{abstract}
While the rapid increase in the fraction of people aged over 65 is driving a substantial increase in the number of people living in nursing homes, there has been very limited previous research carried out on how residents of nursing homes perceive their thermal environment and there is a lack of thermal comfort guidelines for the aged care sector. This article reports on a study to investigate thermal perceptions, preferences and adaptive behaviours of occupants in five nursing homes. Participants were asked to complete a questionnaire while local environmental parameters were monitored in their near proximity using portable equipment. Not all the facilities in the study provided a thermally comfortable environment for occupants at all times, and indoor air temperatures were found to range between $17.2^{\circ} \mathrm{C}$ and $31.6^{\circ} \mathrm{C}$ over the course of the study. As a result, participants adopted a range of adaptive behaviours to compensate for unsatisfactory thermal comfort conditions, such as adjustment of their clothing and the use of ceiling and portable fans in summer. Residents were more tolerant of temperature variations than staff or visitors and both the estimated neutral and preferred temperatures were higher for residents than for non-residents. The findings of this study are likely to have practical implications for all the stakeholders in the aged care sector. The results may also be used to inform the design of new facilities and the assessment of thermal comfort conditions in existing nursing homes.
\end{abstract}

\section{Keywords}

nursing, occupants, homes, behaviours, adaptive, thermal, perceptions, preferences

\section{Disciplines}

Engineering | Science and Technology Studies

\section{Publication Details}

Tartarini, F., Cooper, P. \& Fleming, R. (2018). Thermal perceptions, preferences and adaptive behaviours of occupants of nursing homes. Building and Environment, 132 57-69. 


\section{Thermal perceptions, preferences and adaptive behaviours of occupants of nursing homes}

\footnotetext{
Federico Tartarini ${ }^{\mathrm{a}}$; Paul Cooper ${ }^{\mathrm{a}}$; Richard Fleming ${ }^{\mathrm{b}}$

${ }^{\text {a }}$ Sustainable Buildings Research Centre (SBRC), University of Wollongong, Innovation Campus, North Wollongong, NSW 2522, Australia.

${ }^{b}$ Faculty of Science, Medicine and Health, University of Wollongong, Wollongong, NSW, Australia.
}

Dr Federico Tartarini, E-mail: ft674@uowmail.edu.au; phone: +61 242392109

Prof. Paul Cooper, E-mail: pcooper@uow.edu.au; phone: +61 242213355

Prof. Richard Fleming, E-mail: rfleming@uow.edu.au; phone: +61 242213422

Correspondence concerning this article should be addressed to Federico Tartarini.

Disclosure: The authors have reported no conflicts of interest.

List of Abbreviations:

Predicted Mean Vote (PMV)

National Construction Code (NCC)

Heating, Ventilation, and Air Conditioning (HVAC)

Predicted Percentage of Dissatisfied (PPD)

Body Mass Index (BMI)

World Health Organization (WHO)

International Organization for Standardization (ISO)

American National Standards Institute (ANSI)

American Society of Heating, Refrigerating and Air-Conditioning Engineers (ASHRAE) 


\section{Abstract}

While the rapid increase in the fraction of people aged over 65 is driving a substantial increase in the number of people living in nursing homes, there has been very limited previous research carried out on how residents of nursing homes perceive their thermal environment and there is a lack of thermal comfort guidelines for the aged care sector. This article reports on a study to investigate thermal perceptions, preferences and adaptive behaviours of occupants in five nursing homes. Participants were asked to complete a questionnaire while local environmental parameters were monitored in their near proximity using portable equipment. Not all the facilities in the study provided a thermally comfortable environment for occupants at all times, and indoor air temperatures were found to range between $17.2^{\circ} \mathrm{C}$ and $31.6^{\circ} \mathrm{C}$ over the course of the study. As a result, participants adopted a range of adaptive behaviours to compensate for unsatisfactory thermal comfort conditions, such as adjustment of their clothing and the use of personal cooling fans in summer. Residents were more tolerant of temperature variations than staff or visitors and both the estimated neutral and preferred temperatures were higher for residents than for non-residents. The findings of this study are likely to have practical implications for all the stakeholders in the aged care sector. The results may also be used to inform the design of new facilities and the assessment of thermal comfort conditions in existing nursing homes.

\section{Keywords}

Older people; thermal comfort; residential aged care facilities; aged care homes; field study; dementia. 


\section{Introduction}

Increased life expectancy has been one the biggest achievements of modern society, however, it is now critically important for countries to implement strategies that ensure that people not only live longer but live healthy and happy lives. As people age they are more likely to experience one or more medical conditions which may worsen over time [1], hence older people often need extra care. Nursing homes are often the source of this extra care, and they should have the capacity to enable people who experience significant decline in capacity, to live in a supporting environment which enhances their health and wellbeing [2]. Nursing homes (also called aged care homes or residential aged care homes) are special-purpose facilities with a domestic-styled environment that provide accommodation and 24-hour support, including assistance with activities of daily living, intensive forms of care and assistance towards independent living to frail and aged residents. Nursing homes in Australia provide care also to those who have dementia [3,4].

Nursing homes can generally be classed as a hybrid building typology [5], with internal spaces catering for a wide range of functions including: residential (bedrooms), offices and commercial (kitchen and laundries). In addition, several different types of occupants (e.g. residents, staff, visitors, etc.) share the same indoor environment [6]. Occupants may have different thermal perceptions and preferences due to variations in their level and type of activity, clothing insulation, age, time spent indoors and medical conditions. A well-designed facility should in principle and practice be able to meet the thermal comfort requirements of all occupants [7].

To date, only a very few thermal comfort studies have been conducted in nursing home environments [8-10] so there is limited evidence on which to base guidelines and recommendations to help aged care sector providers understand the thermal requirements of residents $[9,11,12]$ and how to design heating ventilation and air conditioning systems in nursing homes [13]. Hence, current technologies used to control Heating, Ventilation, and Air Conditioning (HVAC) systems in nursing homes may be inadequate for people with decreased cognitive functions [11] and because limited thermal comfort guidelines are available, the control of the thermal environment in nursing homes is likely to rely on ad hoc approaches [14]. 
Fanger, who was one of the most important contributors to the development of a predictive model for whole body thermal comfort, the Predicted Mean Vote (PMV) model [15], claimed that there is no significant difference between the thermal comfort conditions preferred by healthy adults aged around 65 years old and those preferred by college-age students [16]. However, over the last decade, several field studies conducted to determine how age affects the thermal perceptions of older people found evidence that conflicts with some of Fanger's findings, and the researchers concluded that age does significantly affect thermal comfort perceptions [8,9,17-19]. Moreover, in 2015, approximately 93\% of all Australian nursing home residents were aged 70 years and over and approximately $63 \%$ of them were aged 85 years and older. Hence, Fanger's model may not be applicable to this cohort of people since his sample was comprised of only healthy adults aged around 65 years old $[11,15]$. Another important consideration is that over half of permanent residents of aged care facilities in Australia have dementia [20], and dementia may alter how such people perceive their environment and it may potentially affect their thermoregulation $[14,19]$.

As a result of the lack of clear evidence as to how older people perceive their thermal environment, the applicability of the leading international thermal comfort standards, ANSI/ASHRAE Standard 552013 [21] and ISO 7730:2005 [22] is limited to healthy adults only [21,22]. ISO 28803 defines the thermal requirements for people with special requirements, including older people. This standard states that older people prefer the same indoor temperature as younger people, but that temperatures on the cool side of thermal neutrality should be avoided when older people are occupying the space, and the PMV should be maintained between 0 and +0.5 [23].

What is however known is that the indoor environment in nursing homes is not only a key factor in providing comfort but that it also affects the wellbeing, health and behaviours of residents [10-12,2428] and productivity of staff [15]. Moreover, the thermal environment plays a central role in reducing frequency and disruptiveness of agitated behaviours in residents with dementia [29].

In Australia the Aged Care Financing Authority is expecting that the residential sector will need to build approximately 76,000 additional places over the next decade [30]. However, until specific guidelines are developed in respect of provision of thermally comfortable indoor environments, many 
nursing homes may continue to be built and operated, that offer less than optimal thermal conditions which may negatively impact the health and wellbeing of residents.

The objectives of this study were therefore: i) to characterise the thermal performance of a number of existing Australian nursing homes; ii) to determine thermal comfort perceptions and preferences of occupants; iii) investigate the applicability of the PMV model to the prediction of the whole body thermal state of occupants in nursing homes; and iv) to establish the most appropriate temperature ranges for occupants' comfort.

\section{Methodology}

Perception of the thermal environment is primarily influenced by environmental and personal parameters, i.e. thermal preferences and behavioural adjustments that people employ to modify and adapt to their environment [17,31]. Hence, the following information/data was collected in the present study:

- indoor environmental parameters;

- physical characteristics of the participants;

- personal/operational parameters;

- perceptions and preferences of participants regarding their thermal environment.

Indoor environmental parameters were measured and logged using a purpose-built and non-intrusive IEQ monitoring Cart, described in [6], while occupants were asked to complete a questionnaire comprising questions about their perceptions and preferences of the indoor environment. The study was approved by the University of Wollongong Human Research Ethics Committee (HE15/235).

\subsection{Sample and Case Study Facilities}

The target population for this study was the occupants of nursing homes. All building occupants (staff members, volunteers, residents and visitors) were included in the study and asked to complete the questionnaire since a well-designed nursing home should provide comfortable thermal conditions for all occupants. Prior to interviewing the residents, the registered nurses who were directly responsible 
for providing care to the residents were interviewed to identify which participants had sufficient cognitive abilities to complete the questionnaire.

The field study was conducted in five nursing homes located in south-eastern NSW. One facility was located in a mild temperate zone (Australian National Construction Code (NCC) Climatic Zone 6 Köppen-Geiger climate classification $\mathrm{Cfb}$ ). While the remaining facilities were all located in a warm temperate zone (NCC Zone 5 - Köppen-Geiger Cfa) [32]. While the highest monthly mean maximum temperatures did not differ significantly between the two locations, the lowest mean minimum temperature was significantly lower in the mild temperate zone.

All the facilities had double brick external walls, with no insulation, and single-glazed windows. Additional key features of the case studies facilities are summarised in Table 1.

Table 1 Key features of the case study facilities.

\begin{tabular}{|c|c|c|c|c|c|}
\hline \multirow{2}{*}{ Facility } & \multirow{2}{*}{$\begin{array}{l}\mathrm{N}^{\circ} \text { of } \\
\text { beds }\end{array}$} & \multirow{2}{*}{ Construction date } & \multicolumn{2}{|c|}{ Bedrooms } & \multirow{2}{*}{$\begin{array}{l}\text { Common areas } \\
\text { heating/cooling }\end{array}$} \\
\hline & & & Heating & Cooling & \\
\hline NH1 & 150 & $\begin{array}{l}\text { First section 1993; second } \\
\text { section 1997; third section } \\
2008\end{array}$ & $\begin{array}{l}\text { Electric convection } \\
\text { radiators, hydronic } \\
\text { radiators, split } \mathrm{A} / \mathrm{C}^{\mathrm{b}}\end{array}$ & $\begin{array}{l}\text { Few rooms were } \\
\text { equipped with split } \\
\mathrm{A} / \mathrm{C}\end{array}$ & $\begin{array}{l}\text { Ducted, split and cassette } \\
\text { A/C }\end{array}$ \\
\hline $\mathrm{NH} 2$ & 90 & 2007 & Split A/C & Split A/C & Ducted A/C \\
\hline $\mathrm{NH} 3$ & 62 & 1955 & Ducted/gas heater & No & Split and cassette $\mathrm{A} / \mathrm{C}$ \\
\hline $\mathrm{NH} 4$ & 40 & $\begin{array}{l}\text { First section } 1968 ; 1985 \\
\text { were added } 40 \text { beds }\end{array}$ & $\begin{array}{l}\text { Electric convection } \\
\text { radiators and hydronic } \\
\text { radiators }\end{array}$ & No & Split A/C dining room \\
\hline NH5 & 101 & 1984 & Hydronic radiators & No & $\begin{array}{c}\text { Split A/C dining room, } \\
\text { cassette } \mathrm{A} / \mathrm{C} \text { installed } \\
2 / 2016\end{array}$ \\
\hline
\end{tabular}

${ }^{a}$ National Construction Code (NCC).

${ }^{\mathrm{b}} \mathrm{A} / \mathrm{C}$ air-conditioning units

\subsection{Data Collection}

Data was collected over two separate periods of time: for the warm season between November 2015 and February 2016; and for the cold season between March 2016 and July 2016. Participants completed a paper-based version of the questionnaire. All surveys were conducted indoors between 9.00a.m. and 5.00p.m. After obtaining a participant's verbal consent the IEQ Cart was placed in the room, within a one-metre radius of the participant. The participant was then asked to resume his or her previous activity, and after a further 12 minutes he/she was asked to complete the questionnaire. The delay of nominally 12 minutes was chosen to ensure that all sensors reached thermal equilibrium with 
the indoor environment [33]. Participants completed the questionnaire while performing normal dayto-day activities and they were asked neither to modify the indoor environment (e.g. turn on/off fans or air conditioning units) nor to modify their clothing insulation or their activity. Each participant completed the questionnaire only once per season.

The questionnaire used comprised two main sections:

- personal information about the participants (e.g. age, height, weight); and

- thermal perceptions and preferences.

Accurate information about the weight of residents was available since they were weighed each week to monitor their health status. Perceptions of the thermal environment were assessed using the questions provided in the Annex A of ISO 10551 [34]. In addition, participants were also asked to report any causes of thermal discomfort.

A symmetrical 7-point scale was used to assess the Personal Thermal State and thermal preference of each participant. The Personal Thermal State was assessed asking participants: "How do you feel at this precise moment? I am ..." using the following scale: -3 "cold," -2 "cool," -1 "slightly cool," 0 "neutral," +1 "slightly warm," +2 "warm," +3 "hot" [34]. This scale is also known as the ASHRAE thermal sensation scale [21]. While the thermal preference of each participant was assessed through the following question: "At this precise moment, would you prefer to be...?" using one of the following scale: -3 “much cooler," -2 “cooler," -1 "slightly cooler," 0 "without change," +1 "slightly warmer," +2 "warmer," +3 "much warmer" [34].

\subsubsection{Assessment of Indoor Environmental Parameters}

Figure 1 shows the portable IEQ monitoring equipment mounted on an 'IEQ Cart', which was used in the present study to measure and log indoor environmental parameters while participants were completing the questionnaire. 

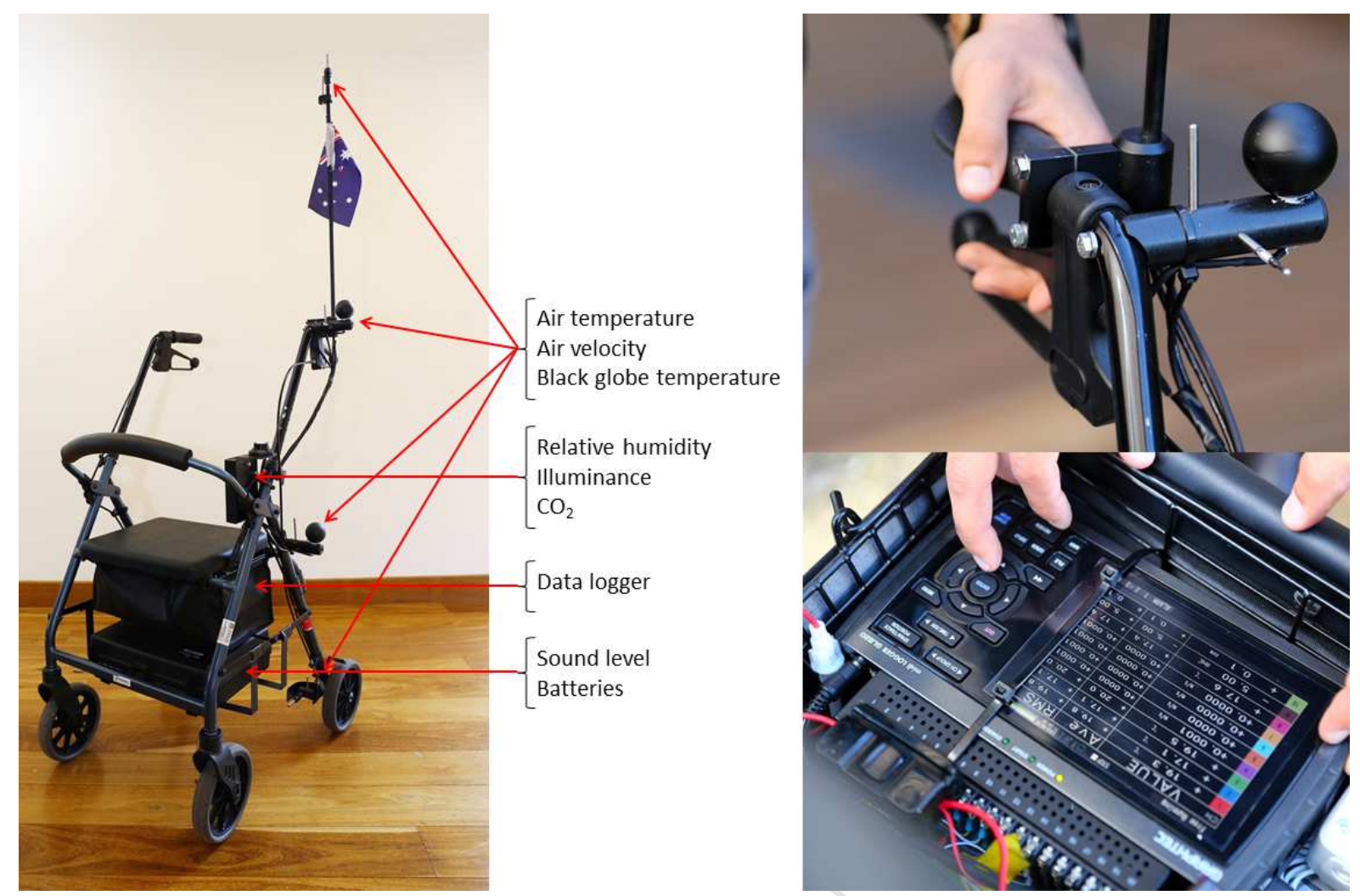

Figure 1 IEQ Cart used to measure and $\log$ IEQ parameters.

The IEQ Cart was specifically designed to blend into the visual context of care for residents, especially for those with dementia. A detailed description of the IEQ cart is provided in Tartarini et al. [6]. During each spot measurement, the following environmental parameters were measured and recorded: indoor air temperature $T_{a}\left({ }^{\circ} \mathrm{C}\right)$, black globe temperature $T_{g}\left({ }^{\circ} \mathrm{C}\right)$, air velocity $V_{a}(\mathrm{~m} / \mathrm{s})$, and relative humidity $\mathrm{RH}(\%)$. The spatially averaged indoor air temperature $\left(\bar{T}_{\mathrm{a}}\right)$, black globe temperature $\bar{T}_{g}\left({ }^{\circ} \mathrm{C}\right)$ and air velocity $\left(\bar{V}_{\text {a }}\right)$ for each participant were calculated based on his/her body position [21,35]. All sensors were calibrated prior to data collection according to manufacturers' recommendations.

\subsection{Data Analysis}

The results for particular participants were divided into two groups; residents and non-residents. For each participant the following indices were calculated: Body Mass Index (BMI), total clothing insulation $\left(I_{\mathrm{clo}}\right)$, operative temperature $\left(T_{\mathrm{o}}\right)$, mean radiant temperature $\left(T_{\mathrm{mrt}}\right)$, metabolic rate $(M)$, PMV and Predicted Percentage of Dissatisfied (PPD). Statistical data analysis was carried out using the IBM SPSS Statistics software (V21, IBM Corporation, Armonk, NY) and MATLAB R2014. 


\subsubsection{Body Mass Index}

For people aged less than 65 years old the classification proposed by the World Health Organization (WHO) was used [36], while the classification proposed by the Queensland Government was used for people aged 65 years and over, since evidence from previous research has shown that the WHO cutoffs for BMI may not be appropriate for older adults [37].

\subsubsection{Metabolic Rate and Total Clothing Insulation}

Total clothing insulation $\left(I_{\mathrm{clo}}\right)$ and metabolic rate $(\mathrm{M})$ were assessed by observing the participant and using the tables in ISO 7730 [22] and ANSI/ASHRAE 55-2013 [21]. Total clothing insulation of the clothing ensemble worn by each participant was determined by adding the insulation level of all individual garments that each participant was wearing [21]. However, because the ANSI/ASHRAE and ISO standards cannot be used to determine the total clothing insulation levels of people who are in bed, $I_{\text {clo }}$ of residents in bed were determined by coupling the data collected (i.e. body position, sleepwear, and bedding) with the most similar combination of beds, bedding and sleepwear provided in the paper published by Lin and Deng [38].

A stepwise linear regression (F-tests) was used to determine the correlation between age group, BMI, metabolic rate, gender and operative temperature and $I_{\mathrm{clo}}$ for non-residents and residents.

\subsubsection{Operative Temperature, Mean Radiant Temperature and PMV}

Mean radiant temperature and operative temperature were calculated for each participant using the equations provided in Annex B and Annex G of ISO 7726 [35].

The PMV model developed by Fanger is a method by which one can estimate the whole body thermal state of a population in a given indoor environment [16]. The Personal Thermal State data of each participant in the present study was compared to the PMV index to determine whether the PMV model as it stands is suitable for estimating the thermal state of residents of nursing homes. In the present study, all the environmental parameters required to estimate the PMV were measured, while metabolic rate and clothing insulation were estimated. The PMV was evaluated using the computer code provided in Appendix B of ANSI/ASHRAE 55-2013 [21]. The code was executed using 
MATLAB R2014. Since the PMV model is not applicable to people who are reclining in bed [21], participants in this situation were excluded from the analysis. The correlation between the Personal Thermal State votes and PMV was determined using a linear regression model [8].

\subsubsection{Neutral Temperature}

The 'neutral temperature' was considered to be the temperature that minimised the physiological temperature regulatory effort of participant [39]. In other words, it was the temperature at which participants reported their perception of feeling "neutral" with respect to their thermal environment. In the available literature the neutral temperature is generally estimated by finding the zero of the linear regression between the Personal Thermal State vote and the operative temperature $[16,17,40,41]$. Hence, this analysis was used to compare the results of the present study with previous studies. However, since the dependent variable is ordinal, the neutral temperature should be estimated using an ordinal regression analysis. The estimated neutral temperature, in the ordinal regression model, was the operative temperature that maximised the likelihood of obtaining a Personal Thermal State vote equal to zero.

\subsubsection{Development of a Thermal Comfort Zone for Occupants of Nursing Homes}

Participants who voted -2 "cool", -3 "cold", +2 "warm" and +3 "hot" in the Personal Thermal State scale were considered to be thermally dissatisfied $[16,17]$. Consequently, Personal Thermal State votes were recoded/reprocessed via a Thermal Satisfaction Index expressed on a 3-point scale, as follows:

- -1, dissatisfied - cold, participants who voted -2 or -3 in the Personal Thermal State scale;

- 0, comfortable, participants who voted $-1,0$ or +1 in the Personal Thermal State scale;

- $\quad+\mathbf{1}$, dissatisfied - warm, participants who voted +2 or +3 in the Personal Thermal State scale.

An ordinal logistic regression model was then used to determine the correlation between the Thermal Satisfaction Index and the operative temperature, because such a model can handle outcome variables that have more than two ordered categories [42]. Thermal comfort zones were determined by calculating the temperatures corresponding to estimated percentages of dissatisfied people equal to 
$10 \%$ and $20 \%$. These temperatures represent the ranges in which more than $90 \%$ and $80 \%$ of participants from each group found the thermal conditions satisfactory $[17,21,43]$.

\section{Results}

A total of 509 participants completed the questionnaire (322 residents and 187 non-residents). The characteristics of the study sample and of the climate conditions indoors in the case study facilities are summarised in Table 2.

Table 2 Characteristics of the study sample.

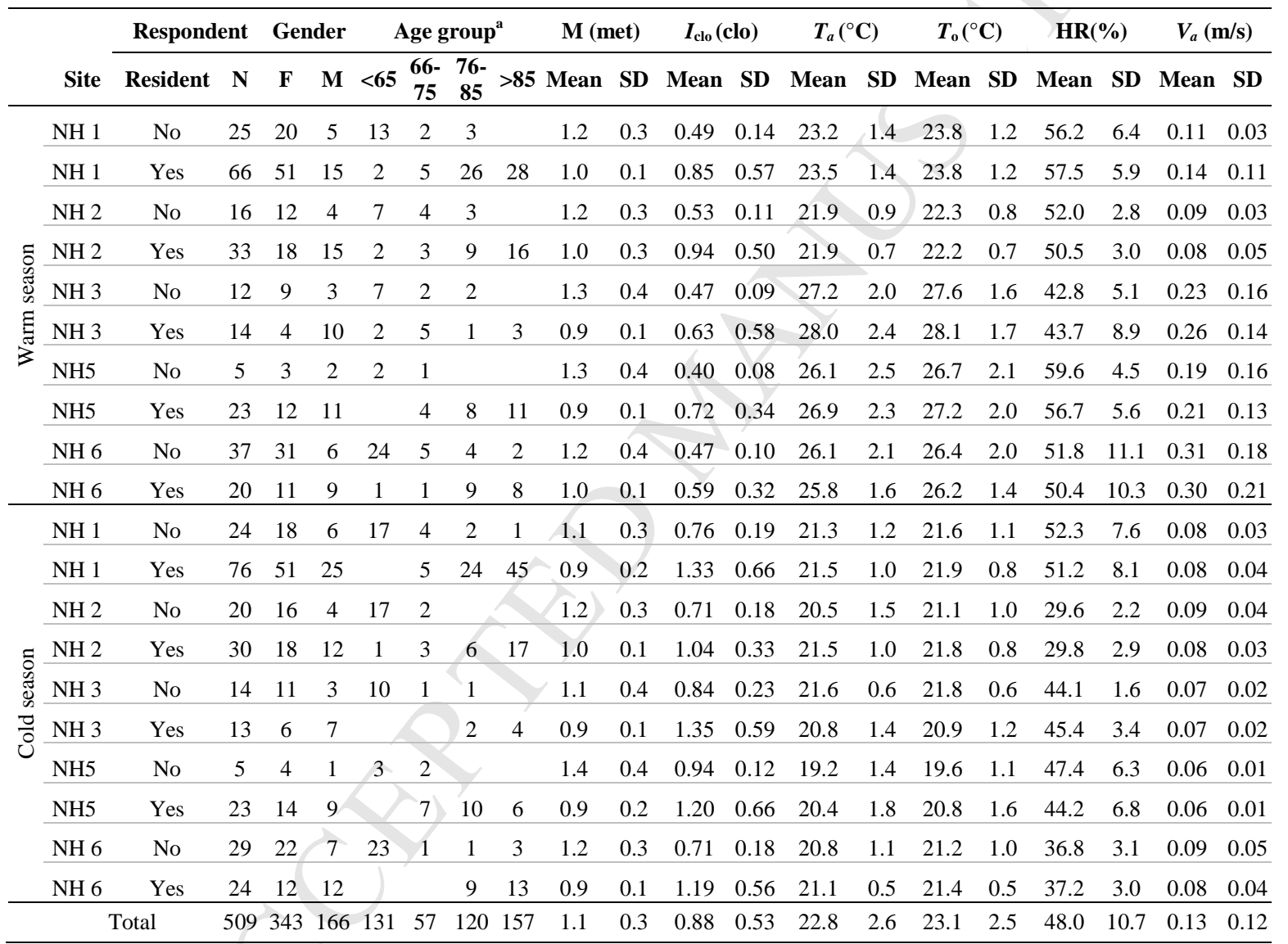

The majority of the participants were female (67\%); while approximately $54 \%$ of the total participants were aged 76 years and over.

\subsection{Clothing Insulation and Personal Thermal State of the Participants}

Clothing insulation varied substantially across participants, ranging from 0.23 clo (summer dress with short sleeves and undergarments) up to 2.87 clo (in bed with blanket and wearing flannel winter clothes). Figure 2 shows the distribution of total clothing insulation grouped by Personal Thermal 
State votes, and Figure 3 presents the data collected from only those participants who were not in bed at the time of the interview. Residents in bed were excluded from Figure 3 since both ANSI/ASHRAE 55-2013 and ISO 7730 thermal comfort standards are not applicable to people in bed and do not provide tables to estimate their total clothing insulation [21,22].

In both the warm and cold seasons, total clothing insulation $\left(I_{\mathrm{clo}}\right)$ varied considerably, especially among those participants who reported feeling "neutral"; suggesting that active adjustment of clothing was an effective thermal adaptive behaviour that participants employed to compensate for various thermal comfort conditions. On average residents wore more clothes than their counterpart to achieve thermal neutrality with the environment. Staff members were also able to actively modify their clothing since they were not required to follow a strict dress code by their employer.
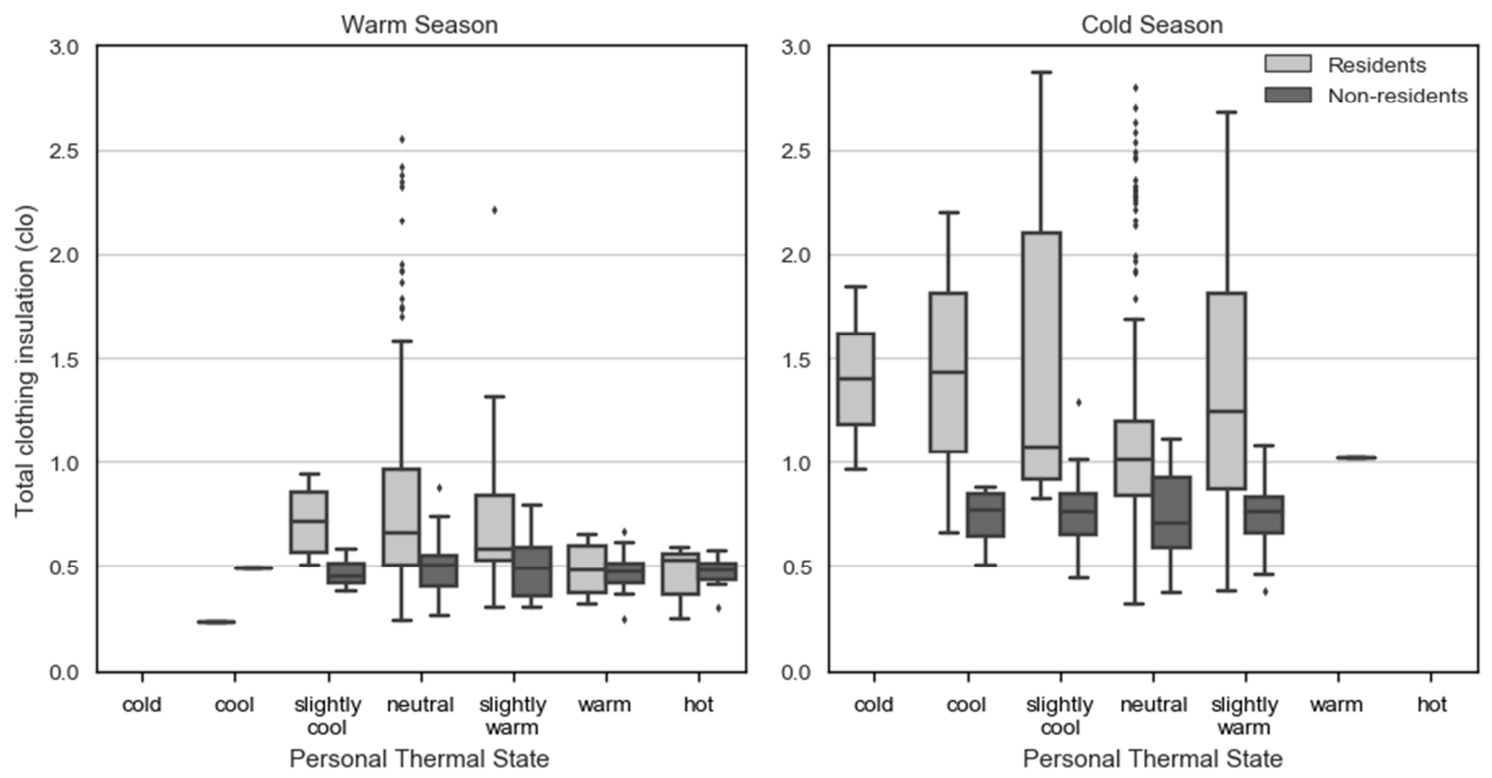

Figure 2 Box plots of total clothing insulation of all participants (including those in bed) grouped by Personal Thermal State vote. 

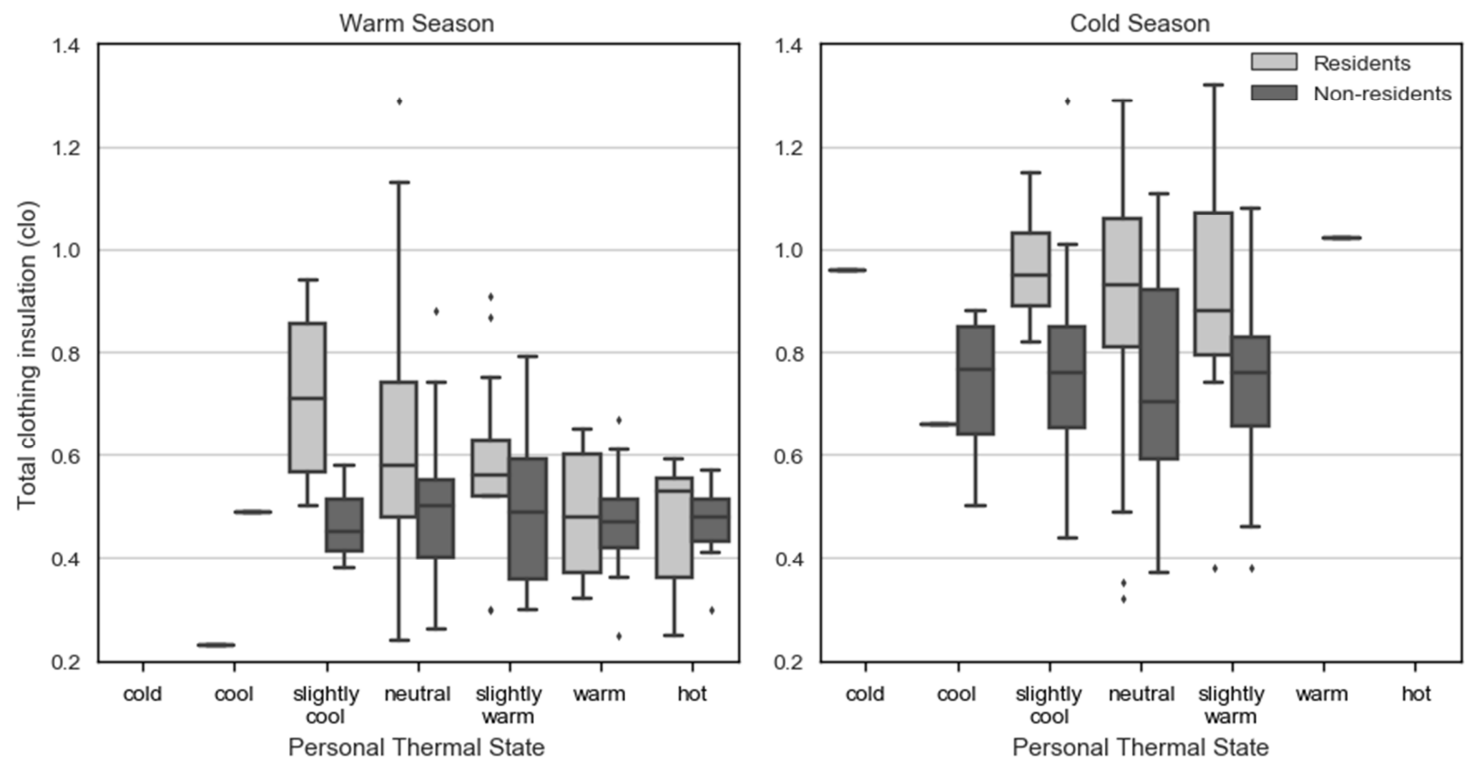

Figure 3 Total clothing insulation of participants who were not in bed, grouped by Personal Thermal State vote.

Figure 4 shows the total clothing insulation of each participant plotted against the indoor operative temperature, and the associated best-fit linear regression equations. Participants were grouped in three main groups: non-residents; residents not in bed; and residents in bed.

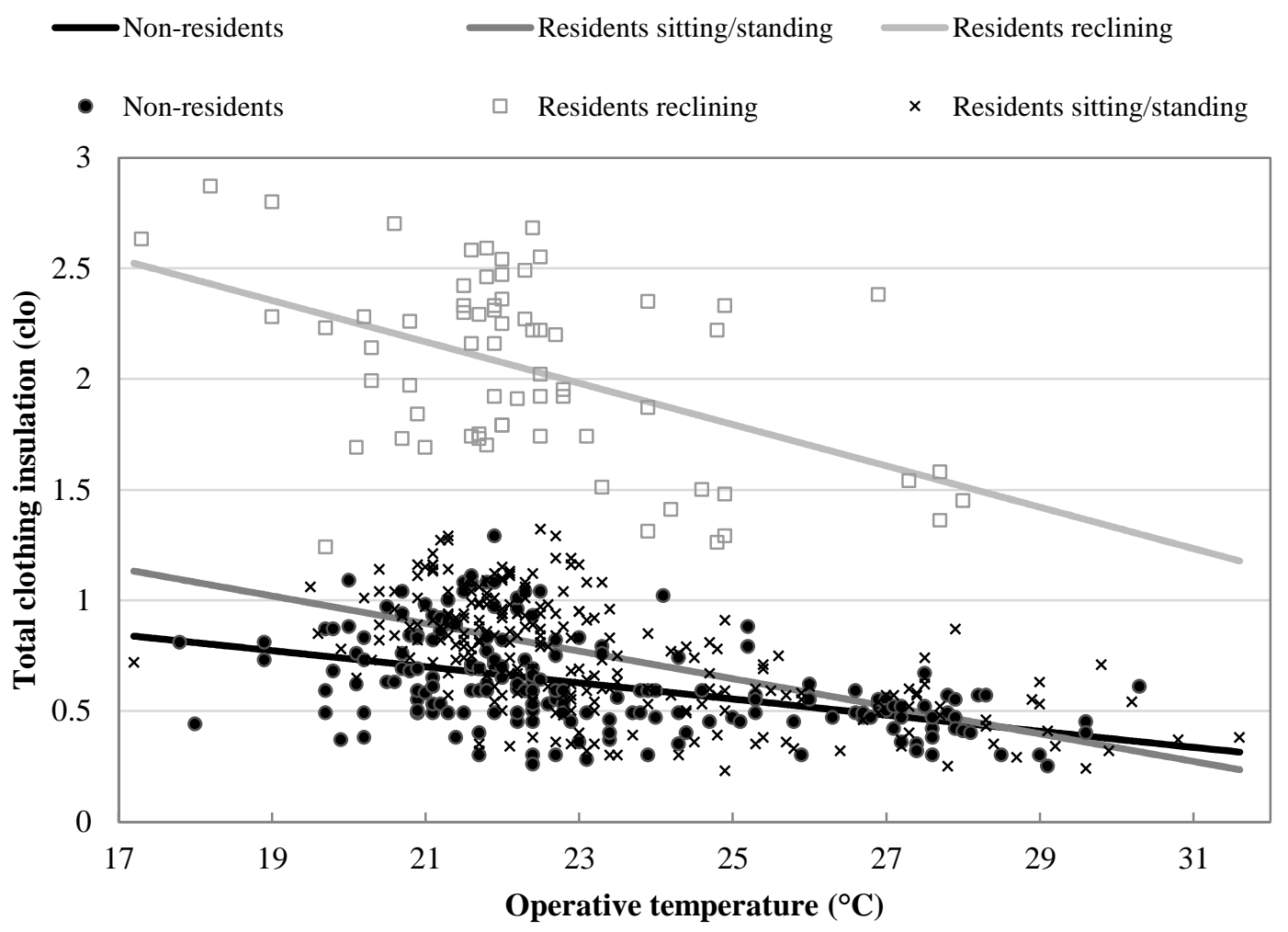

Figure 4 Total clothing insulation plotted versus the operative temperature with linear regression lines of best-fit results. 
The equations of the three linear regression equations presented in Figure 4 were as follows: nonresidents $I_{\mathrm{clo}}=1.46-0.0364 T_{o}\left(\mathrm{R}^{2}=0.22\right)$; residents not in bed $I_{\mathrm{clo}}=2.20-0.0623 T_{o}\left(\mathrm{R}^{2}=0.35\right)$; residents in bed $I_{\text {clo }}=4.13-0.0934 T_{o}\left(\mathrm{R}^{2}=0.23\right)$. Operative temperature accounted for less than $35 \%$ of the total variance in the three models.

Data collected from 113 non-residents and 296 residents was therefore used to determine how total clothing insulation varied as a function of BMI, operative temperature, age group, gender and metabolic rate. It should be noted that some participants were excluded from the analysis since data on their body weight, height or age was not available. The results showed that the total clothing insulation of non-residents $\left(I_{\mathrm{clo}}\right)$ was negatively correlated with an increase in metabolic rate (B $=-0.140, p=.01)$ and operative temperature $(\mathrm{B}=-0.047, p<.01)$. Moreover, non-residents with a mid-range BMI (BMI - Normal) on average wore 0.093 clo more clothing than those with a higher BMI (BMI - Obese), and younger participants wore fewer clothes than older ones.

The total clothing insulation of residents was negatively correlated with an increase in operative temperature $(\mathrm{B}=-0.065, p<.01)$ and their clothing insulation increased as a function of age. Residents aged $85(\mathrm{~B}=0.123, p<.01)$ years old and over wore more clothes than residents aged less than 75 years old.

Gender was not found to be a significant predictor of total clothing insulation for either group of participants.

\subsection{Air Velocity}

Clothing adjustment was not the only behavioural adjustment employed by participants to adapt to microclimatic conditions. Figure 5 and Figure 6 show how indoor air velocity increased with increasing indoor air operative temperature, which was likely due to changes in occupant control of their local environment (e.g. opening windows or switching on personal cooling fans). The figures also display the acceptable ranges of operative temperature as a function of average air velocity for $I_{\mathrm{clo}}=0.5 \mathrm{clo}$ (summer clothing) and $I_{\mathrm{clo}}=1.0 \mathrm{clo}$ (winter clothing) as defined by the ANSI/ASHRAE 55-2013 [21]. During the warm season the average air speed was positively correlated $(p<.01)$ with 
an increase in the operative temperature. Suggesting that, both residents and non-residents effectively used personal cooling fans to compensate for warm indoor air temperatures. On the other hand, it was observed that fans were not used during the cold season or when indoor temperatures lower than $23^{\circ} \mathrm{C}$ were recorded during the warm season.
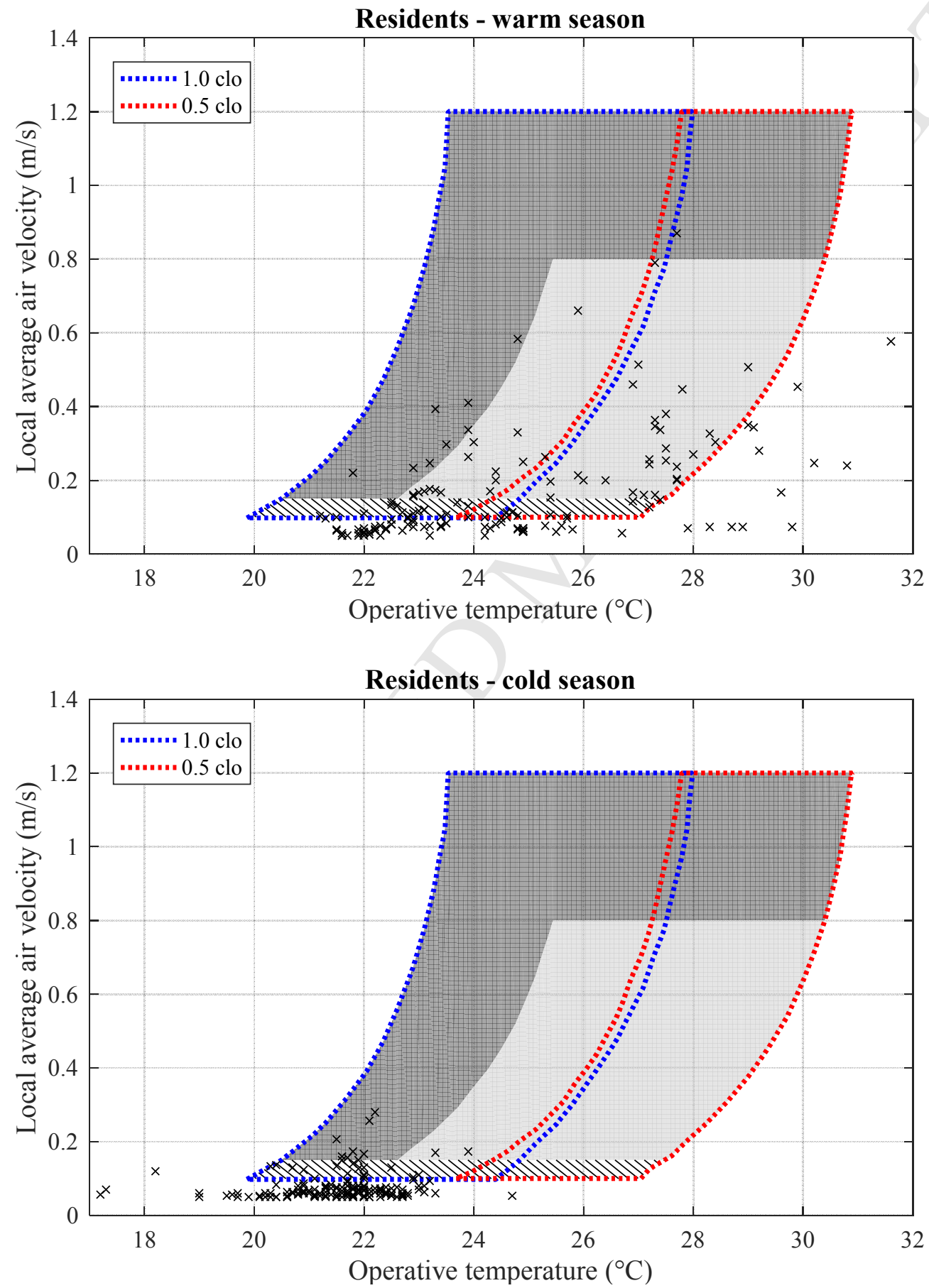

Figure 5 Average local air velocity plotted against indoor operative temperature (adjacent to residents).

The figure also shows the acceptable ranges of operative temperature and average air velocities as defined by ANSI/ASHRAE 55-2013 Standard for 1.0 and 0.5 clo. The lightly shaded region indicates acceptable conditions in rooms where occupants do not have control over the local air velocity, the darker 
region is for when occupants do have this control, and the hatched region shows the 'still air' comfort zone.
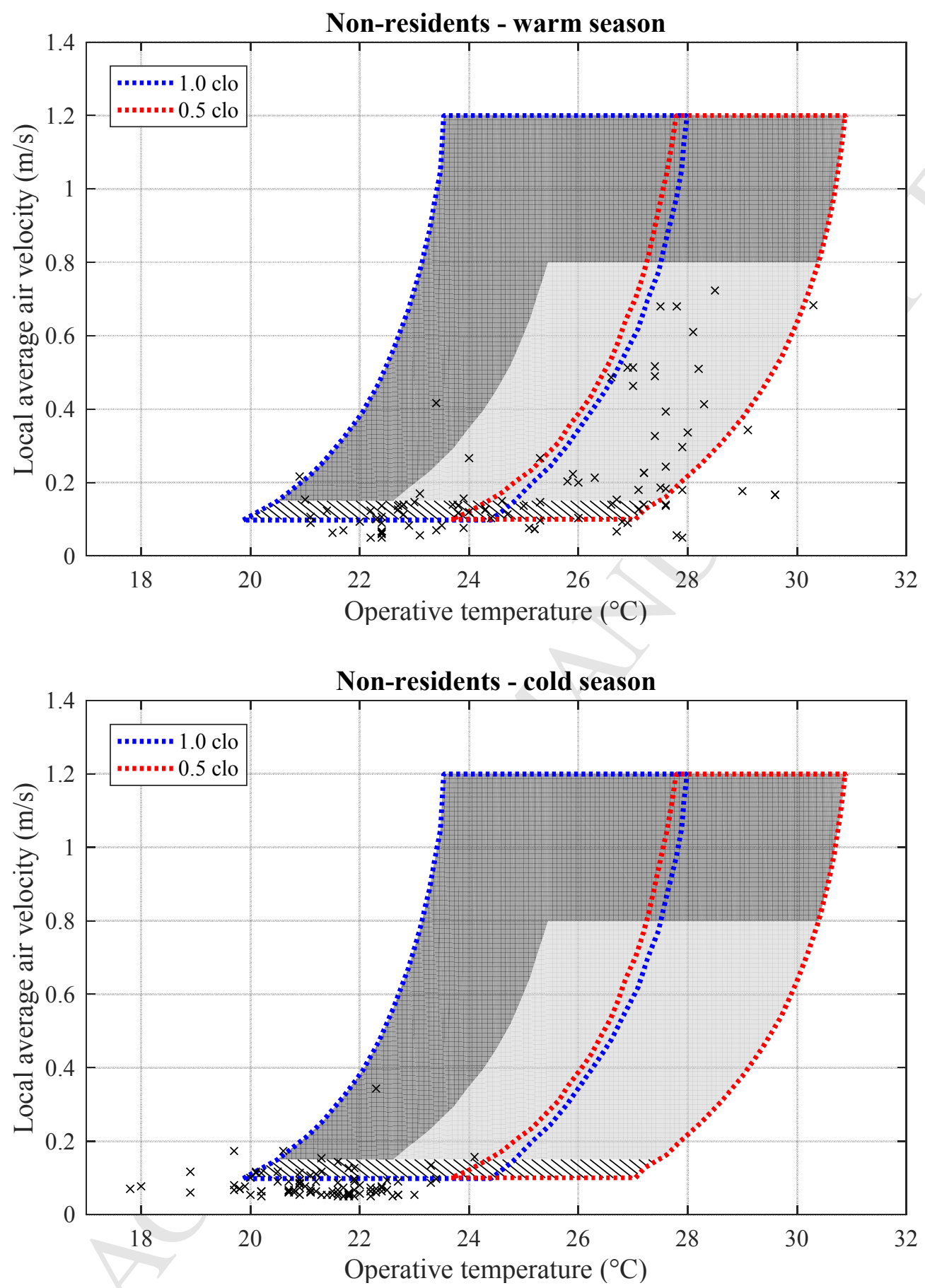

Figure 6 Average air velocity plotted against the indoor operative temperature, non-residents data only.

Figure 5 and Figure 6 also show that during the cold season, the great majority of experimental points fell within the winter comfort range $(1.0 \mathrm{clo})$ and indoor operative temperatures rarely exceeded $23^{\circ} \mathrm{C}$. While, during the warm season, participants were exposed to temperatures on the cold side of the ANSI/ASHRAE 55-2013 Standard summer thermal comfort zone since air conditioning units had 
relatively low temperature set-points. Thus, in light of the results presented in Section 3.1, it would appear that participants wore extra layers of clothes to compensate for cooler temperatures caused by the low set-points on the HVAC systems.

During the warm season $53 \%$ of residents and $40 \%$ of non-residents were exposed to operative temperatures colder than those recommended by the ANSI/ASHRAE 55-2013 Standard for summer clothing, however, less than $4 \%$ of both residents and non-residents voted $\leq-1$ in the Personal Thermal State scale. While, $57 \%$ of non-residents perceived the environment to be warmer than neutral (Personal Thermal State $\geq 1$ ) despite the fact that only $13 \%$ of the data were located in the warmer region of the ANSI/ASHRAE 55-2013 Standard comfort zone. Non-residents wore light clothes during the warm season (Figure 3) and their mean metabolic rate was 1.23 met $(\mathrm{SD}=0.34$ met), which suggests that many of them preferred temperatures colder than those indicated by ANSI/ASHRAE 55-2013 Standard. Residents were also generally comfortable when exposed to relatively cold temperatures during the warm season since $78 \%$ of them (metabolic rate mean $=0.97$; $\mathrm{SD}=0.14)$ reported feeling "normal." Nonetheless, many of them had to employ adaptive strategies (i.e. wearing winter clothes in summer) in order to feel comfortable in the prevailing indoor microclimate.

\subsection{Neutral Temperature}

Figure 7 shows Personal Thermal State votes plotted against the indoor operative temperature, where data has been 'binned' (clustered) in $1^{\circ} \mathrm{C}$ intervals. The radius of each bubble is directly proportional to the number of data points in each temperature 'bin'. Participants from both groups considered the indoor environment to be comfortable over a wide range of temperature, i.e. between $17^{\circ} \mathrm{C}$ and $30^{\circ} \mathrm{C}$. However, residents were found to be more tolerant than non-residents since, excluding one outlier, they reported that the environment was "warm" or "hot" only when temperatures exceeded $26.5^{\circ} \mathrm{C}$. While, some non-residents reported feeling "warm" when the indoor temperature exceeded $22.5^{\circ} \mathrm{C}$. 


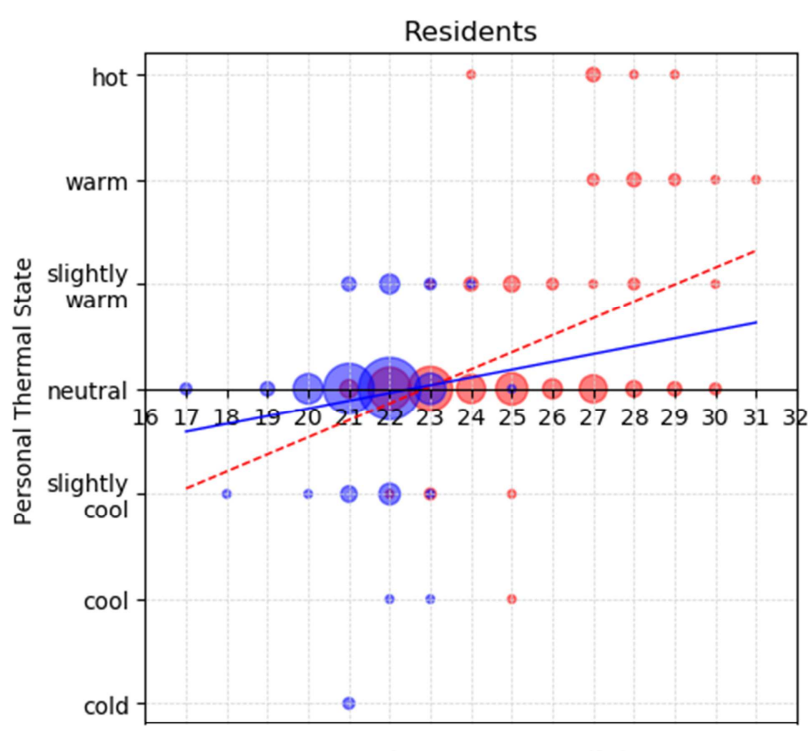

Operative temperature $\left({ }^{\circ} \mathrm{C}\right)$

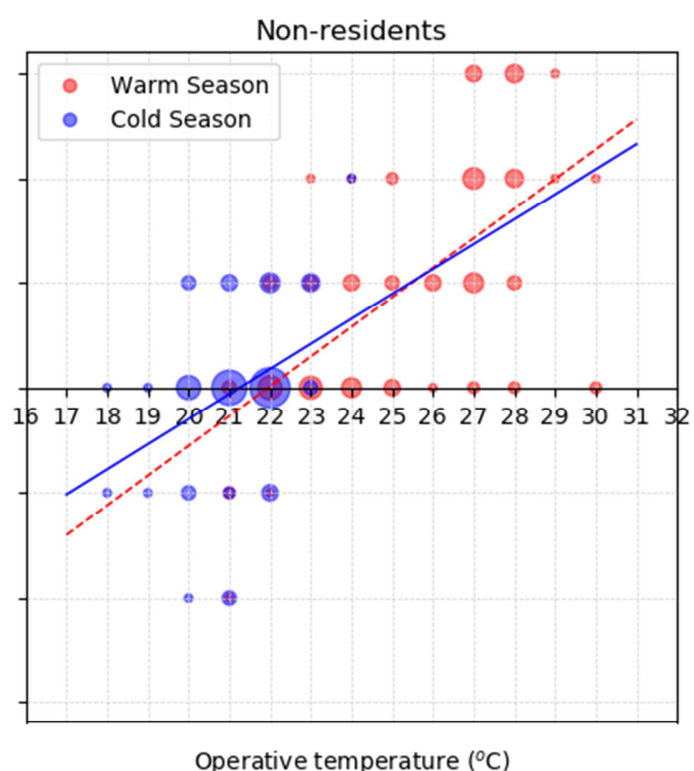

Operative temperature $\left(^{\circ} \mathrm{C}\right)$

Figure 7 Personal Thermal State votes of residents and non-residents plotted against binned indoor operative temperature data. Indoor operative temperature was binned on $1^{\circ} \mathrm{C}$ interval. Regression lines for the cold (blue line) and warm (red dashed line) seasons are also presented.

The neutral temperatures estimated using a linear regression analysis were: i) $22.9^{\circ} \mathrm{C}$ for residents, warm season; ii) $22.0^{\circ} \mathrm{C}$ for non-residents, warm season; iii) $21.2^{\circ}$ for non-residents, cold season. No significant correlation between the Personal Thermal State and operative temperature was found for residents in the cold season, as a consequence the neutral temperature was not estimated. This was possibly because only 10 residents out of a total of 187 were exposed to temperatures lower than $20^{\circ} \mathrm{C}$ during the cold season.

The neutral temperatures estimated with the linear model were approximately $0.2^{\circ} \mathrm{C}$ higher than the neutral temperatures determined using an ordinal model.

\subsection{Thermal Preference and Preferred Temperatures}

Figure 8 shows the thermal preference votes plotted against indoor operative temperature. During the warm season $47 \%$ of residents wanted the temperature to be cooler only when the indoor operative temperature exceeded $26.5^{\circ} \mathrm{C}$, while $80 \%$ of non-residents that were exposed to temperatures higher than $23.5^{\circ} \mathrm{C}$ wanted conditions to be cooler. 
As a consequence, the preferred temperatures estimated using linear regression analyses were: i)

$23.2^{\circ} \mathrm{C}$ for residents, warm season; ii) $21.7^{\circ} \mathrm{C}$ for non-residents, warm season; iii) $21.5^{\circ}$ for nonresidents, cold season.
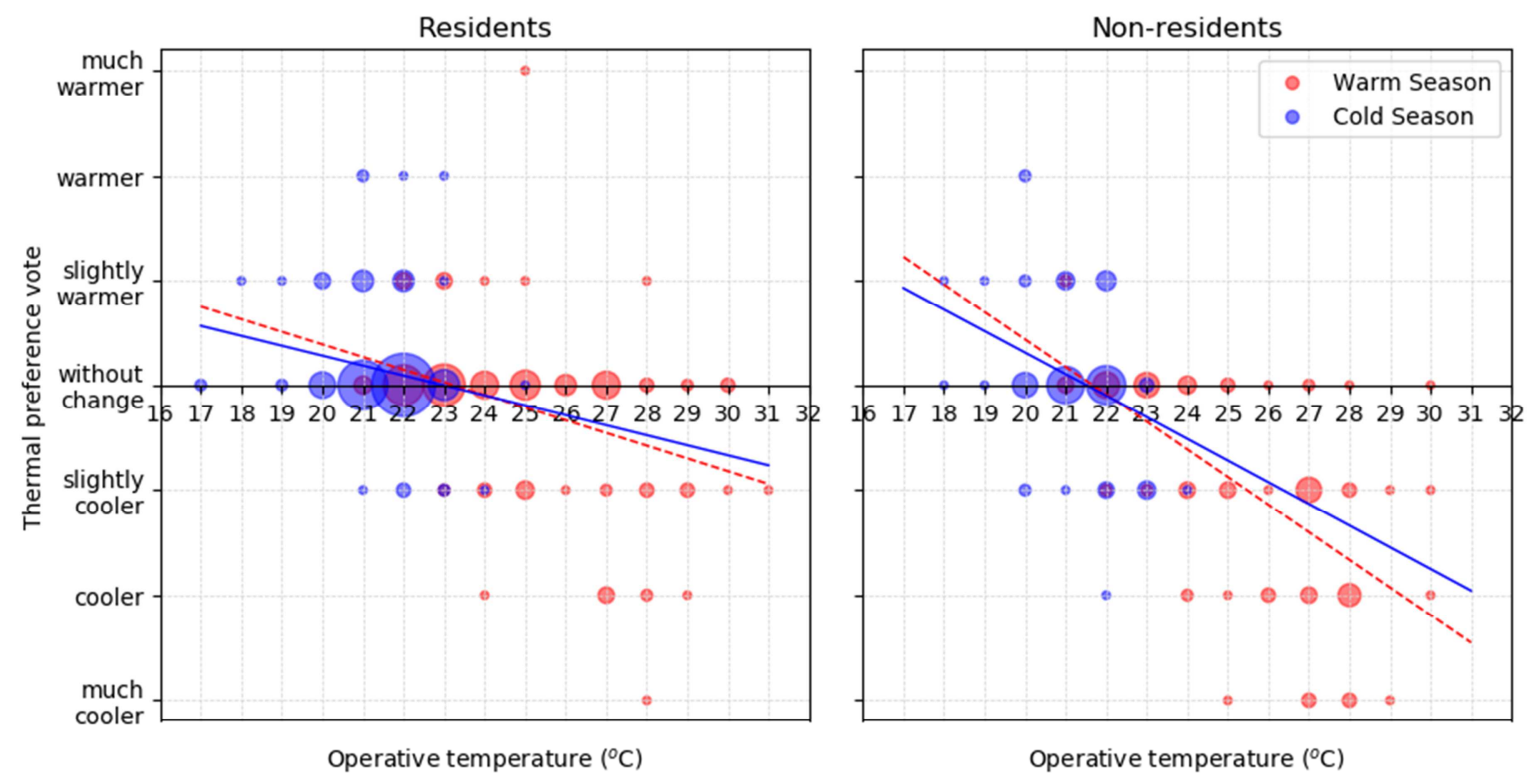

Figure 8 Thermal preference votes of residents and non-residents plotted against binned indoor operative temperature data. Indoor operative temperature was binned at $1^{\circ} \mathrm{C}$ intervals.

\subsection{Development of a Thermal Comfort Zone for Occupants of Nursing Homes}

Figure 9 shows the PPD curves for residents and non-residents, together with the $95 \%$ confidence intervals, and horizontal lines indicating the ranges below which $80 \%$ and $90 \%$ of the participants were estimated to be satisfied with their indoor operative temperature. 


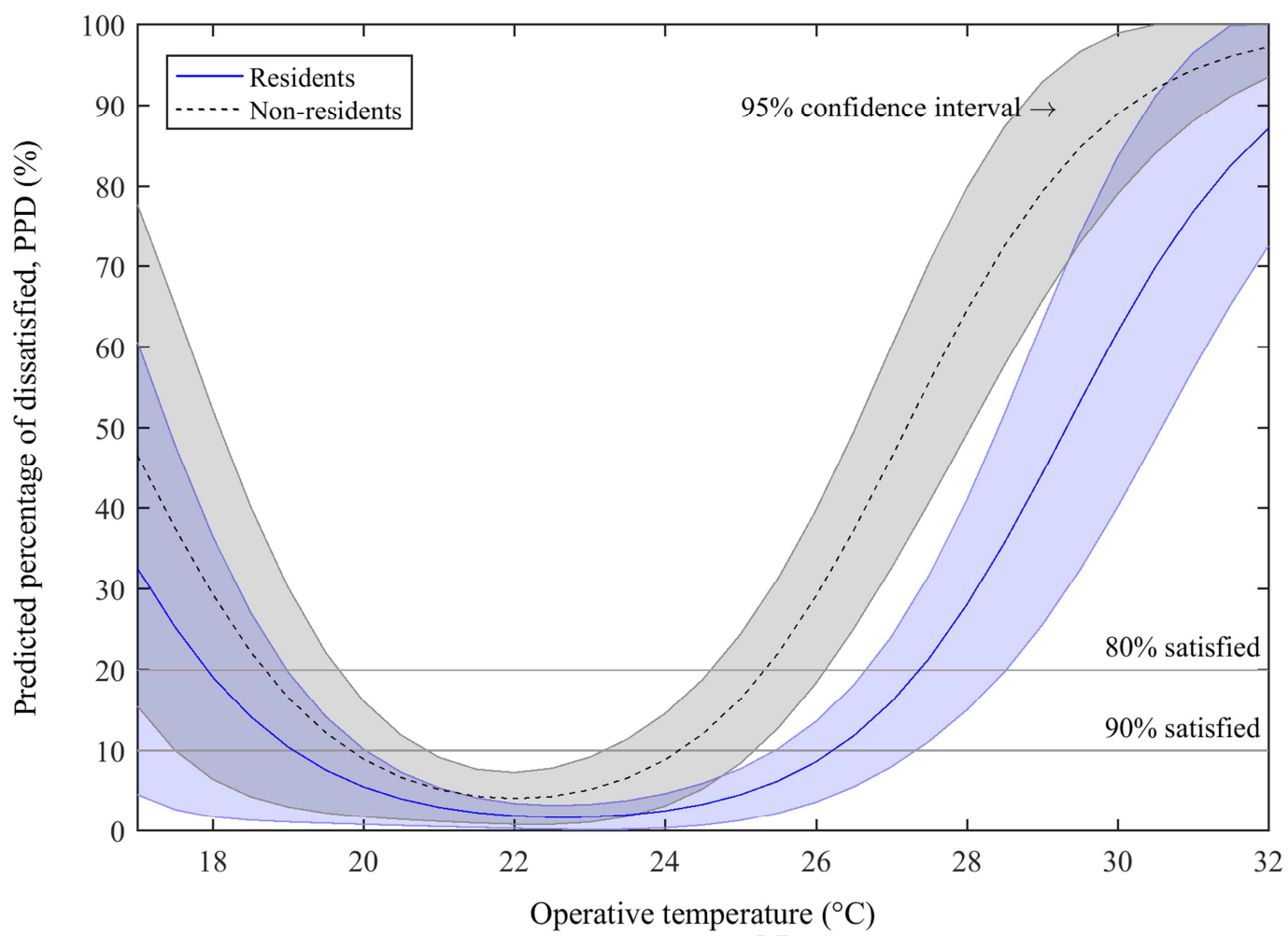

Figure 9 Estimated PPD values for residents and non-residents as a function of operative indoor air temperature $\left({ }^{\circ} \mathrm{C}\right)$. Estimated regression curves were plotted using the regression coefficients estimated by the ordinal logistic regression model.

The minimum PPD for residents was $2.0 \%$ (operative temperature $=22.6^{\circ} \mathrm{C}$ ) and for non-residents was $4 \%$ (operative temperature $=22.0^{\circ} \mathrm{C}$ ). Table 3 shows the thermal comfort zones calculated for residents and non-residents for $\mathrm{PPD}=20 \%$ and $\mathrm{PPD}=10 \%$.

Table 3 Comparison of thermal comfort zones estimated for residents and non-residents for PPD $=\mathbf{2 0} \%$ and PPD $=10 \%$.

\begin{tabular}{|c|c|c|c|c|}
\hline PPD & $\begin{array}{l}\text { Acceptability } \\
\text { limit }\end{array}$ & Author & Participant group & $\begin{array}{l}\text { Thermal comfort } \\
\text { zone }\end{array}$ \\
\hline \multirow{4}{*}{$20 \%$} & \multirow{4}{*}{$80 \%$} & Present study & Residents & $17.9-27.4^{\circ} \mathrm{C}$ \\
\hline & & Present study & Non-residents & $18.7-25.3^{\circ} \mathrm{C}$ \\
\hline & & \multirow{2}{*}{$\begin{array}{l}\text { Hwang and Chen } \\
\text { (2010) }\end{array}$} & $\begin{array}{l}\text { Elderly people aged } 60 \text { years and over living in } \\
\text { their homes - summer }\end{array}$ & $23.2-27.1^{\circ} \mathrm{C}$ \\
\hline & & & $\begin{array}{l}\text { Elderly people aged } 60 \text { years and over living in } \\
\text { their homes - winter }\end{array}$ & $20.5-25.9^{\circ} \mathrm{C}$ \\
\hline \multirow{4}{*}{$10 \%$} & \multirow{4}{*}{$90 \%$} & Present study & Residents & $19.1-26.2^{\circ} \mathrm{C}$ \\
\hline & & Present study & Non-residents & $19.8-24.2^{\circ} \mathrm{C}$ \\
\hline & & ISO 7730 & General population & $20-26^{\circ} \mathrm{C}$ \\
\hline & & Wong et al. (2009) & Residents of nursing homes - summer & $25.6-26.3^{\circ} \mathrm{C}$ \\
\hline
\end{tabular}




\subsection{Predicted Mean Vote (PMV) versus Personal Thermal State}

The regression coefficients estimated from the linear regression analysis are shown in Table 4. The results show that PMV was positively correlated with Personal Thermal State data, however, for PMV $=0$ the predicted Personal Thermal State vote for residents and non-residents was 0.369 and 0.763 , respectively. In other words, when the Personal Thermal State vote was 0 the PMV was equal to -1.1 and -1.2 for residents and non-residents, respectively. Overall participants in this study were comfortable when their estimated PMV was negative.

Table 4 Regression coefficients estimated from the linear model.

\begin{tabular}{llcc}
\hline Model $^{\mathrm{a}}$ & $\mathrm{B}$ & Std. Error & Sig. \\
\hline $\begin{array}{l}\text { Residents (254 participants) }^{b} \\
\text { Intercept }\end{array}$ & .369 & .058 & .000 \\
PMV & .338 & .059 & .000 \\
\hline $\begin{array}{l}\text { Non-residents (187 participants) } \\
\text { Intercept }\end{array}$ & .763 & .072 & .000 \\
PMV & .613 & .068 & .000 \\
\hline $\begin{array}{l}\text { a. Dependent variable = Personal Thermal State. } \\
\text { b. Residents who were reclining were excluded from the model. }\end{array}$
\end{tabular}

\section{Discussion}

\subsection{Adaptive Behaviours}

Few thermal comfort studies have been conducted in nursing homes previously, resulting in limited evidence being available to which the present results could be compared. Thus, results of the present study were compared with findings obtained by Hwang and Chen [17] who investigated the thermal sensations of older people in Taiwan living in their homes. Hwang and Chen also observed that in summer window-opening, clothing adjustment and use of personal cooling fans were the most common strategies used by the participants for adaptation when thermal conditions were uncomfortable. While in winter $64 \%$ of their participants alleviated thermal discomfort by adjusting their clothing insulation [17]. Hwang and Chen [17] also investigated the correlation between total clothing insulation and operative temperature, however, they did not include other predictors in their analysis. They found that their data was correlated by a linear regression of $I_{\text {clo }}$ against $T_{\mathrm{o}}$ for the older people where: $I_{\text {clo }}=2.37-0.07 T_{o}\left(\mathrm{R}^{2}=0.70\right)$, which closely aligns with the results of the present 
study, i.e. $I_{\text {clo }}=2.20-0.0623 T_{o}$ (with operative temperature as only predictor, $\mathrm{R}^{2}=0.35$ ). Hwang and Chen also observed that older people and their general adult cohort usually wore the same level of clothing insulation when $T_{o}$ exceeded $30^{\circ} \mathrm{C}$ and that the older participants required an increase of 0.1 clo for a decrease of $1.4^{\circ} \mathrm{C}$ in the operative temperature [17]. In the present study, both groups wore the same levels of total clothing insulation above a temperature of $T_{\mathrm{o}}=28.5^{\circ} \mathrm{C}$, and residents had to increase their $I_{\text {clo }}$ by 0.1 clo for a decrease in temperature of $1.6^{\circ} \mathrm{C}$ (where operative temperature was taken as the only predictor in the linear regression).

The great majority of the residents in the present study reported that they felt thermally neutral during the warm and cold seasons, $78 \%$ and $82 \%$, respectively. Similar results were previously obtained by Wong et al. [9] who examined the thermal acceptance of 384 older people living in 19 nursing homes in Hong Kong and by Yang et al. [8] who studied thermal environmental conditions for elderly people living in 26 nursing homes in Korea. However, as Wong et al. observed, high percentages of acceptance are not always synonymous with good thermal comfort conditions [9]. For example, in the present study some residents reported that they had to wear extra clothes to compensate for low HVAC set-point temperatures in summer.

\subsection{Neutral Temperature and Preferred Temperature}

In the present study show that residents were tolerant of a wider range of indoor temperatures than non-residents. Schellen et al. [44] studied the difference between thermal comfort perceived by young adults and elderly participants, and also found that the latter preferred warmer temperatures than the former [44].

In the present study non-residents were also more affected by temperature variations than their counterparts. During the warm season, the Personal Thermal State vote for non-residents increased by 1 unit for an increase of only $3.5^{\circ} \mathrm{C}$ in the operative temperature, as compared to $5.7^{\circ} \mathrm{C}$ for residents.

However, it should be noted that in reality the regression coefficients reflect the Personal Thermal State of participants after they had, in all likelihood, already employed adaptive strategies (e.g. adjusted their clothing and local air velocity). Hence, the difference observed may be partially 
explained by the fact that residents could employ more adaptive strategies than non-residents and they could modify their activity level and clothing as a function of the indoor air temperature.

Hwang and Chen [17] also observed that in summer the neutral temperature for the elderly was $0.4^{\circ} \mathrm{C}$ higher than for the adult population, however, in their study, the neutral temperature for the elderly was $25.2^{\circ} \mathrm{C}$, which is $2.3^{\circ} \mathrm{C}$ higher than the neutral temperature in this study. Hwang and Chen [17] also found that the elderly participants would increase their Personal Thermal State vote in summer of by unit for every $2.6^{\circ} \mathrm{C}$ increase in the operative temperature. While, Wong et al. [9] also estimated that the neutral temperature for residents who were living in Hong Kong nursing homes was $25.8^{\circ} \mathrm{C}$. Table 5 compares the results obtained in the present study with the neutral temperatures estimated by Hwang and Chen [17] and Wong et al. [9].

Table 5 Neutral temperatures estimated for the elderly population.

\begin{tabular}{|c|c|c|c|c|}
\hline Author & Location & Participants & $\begin{array}{l}\text { Number of } \\
\text { participants }\end{array}$ & $\begin{array}{c}\text { Estimated neutral } \\
\text { temperature during the warm } \\
\text { season }\end{array}$ \\
\hline Present study & $\begin{array}{l}\text { South-eastern New } \\
\text { South Wales, } \\
\text { Australia }\end{array}$ & Residents of nursing homes & 322 & $22.9^{\circ} \mathrm{C}$ \\
\hline $\begin{array}{l}\text { Hwang and } \\
\text { Chen (2010) }\end{array}$ & Taiwan & $\begin{array}{c}\text { Elderly people aged } 60 \text { years } \\
\text { and over living in their } \\
\text { homes }\end{array}$ & 87 & $25.2^{\circ} \mathrm{C}$ \\
\hline $\begin{array}{c}\text { Wong et al. } \\
\text { (2009) }\end{array}$ & Hong Kong & Residents of nursing homes & 384 & $25.8^{\circ} \mathrm{C}$ \\
\hline
\end{tabular}

Differences in the neutral temperatures found by Hwang and Chen [17] and Wong et al. [9], as compared to those found in the present study may be partially explained by the fact that the previous studies were conducted in a different geographical and climatic region (i.e. Hong Kong and Taiwan) which was much warmer than that of the present study. However, the study of how outdoor climate affects the neutral temperatures of people is outside the scope of the present research.

\subsection{Thermal Comfort Zones}

In the present study the minimum PPD from the regression curve for residents was $2 \%$ (operative temperature $22.6^{\circ} \mathrm{C}$ ) and for non-residents was $4 \%$ (operative temperature $22.0^{\circ} \mathrm{C}$ ). Similar results were previously obtained by Hwang and Chen [17] who determined that the minimum PPD for elderly people was $3 \%$ and it was lower than for non-elderly people. Furthermore, the minimum PPD 
for non-residents in the present study $(4 \%)$ was very similar to the minimum PPD $=5 \%$ calculated in ISO 7730 and ANSI/ASHRAE 55-2013 standards [21,22].

Although residents in the present study were apparently more tolerant than non-residents to temperature variations, previous studies have shown that older people are among those who suffer the most when exposed to cold or hot temperatures [45-49]. Thus, thermal comfort standards [21,23] recommend that a narrow temperature range $(90 \%$ acceptability, $\mathrm{PPD}=10 \%)$ should be maintained when elderly people, and people with special requirements, are using an indoor space. While, the $80 \%$ acceptability temperature range $(\mathrm{PPD}=20 \%)$ is recommended for other occupants. High or low environmental temperatures should also be avoided since ageing; dementia and pharmacological interventions have found to be correlated with decreased sensitivity to temperature changes and may impair people behavioural and thermoregulatory responses $[24,50]$.

Results obtained in the present study, and results obtained by previous researchers who have studied the thermal comfort requirements of elderly people and residents of nursing home are summarised in Table 3. The table shows that the maximum temperature recommended by ISO 7730 for the general population $\left(26^{\circ} \mathrm{C}\right)$ and by Wong for residents of nursing homes $\left(26.3^{\circ} \mathrm{C}\right)$ did not differ significantly from the maximum temperature estimated in the present study $\left(26.2^{\circ} \mathrm{C}\right)$. Whereas the lower threshold temperature estimated in the present study was significantly lower than those recommended by Hwang and Chen [17] and by ISO 7730 [22].

As a consequence of this comparison, and because both ISO 7730 and the World Health Organization suggest that elderly people should not be exposed to temperatures lower than $20^{\circ} \mathrm{C}$ [51], the present authors conclude that a comfort band between $20.0^{\circ} \mathrm{C}$ and $26.2^{\circ} \mathrm{C}$ would appear to be appropriate and desirable for residents living in nursing homes. However, the way in which this is operationalised is not a trivial issue, particularly with respect to control of HVAC systems in different seasons.

As a starting point one might adopt a strategy such that the temperature in winter in nursing homes is maintained at $21.5 \pm 1.5^{\circ} \mathrm{C}$; while, the temperature in summer could be selected as a function of room type, type of occupancy and availability of personal cooling fans. In residents' rooms which are 
equipped with fans, indoor temperature should be maintained at $24.5 \pm 1.5^{\circ} \mathrm{C}$, while colder temperatures (e.g. $23 \pm 1.5^{\circ} \mathrm{C}$ ) should be maintained rooms used by staff which are involved in more demanding tasks (i.e. nurses stations). However, further research needs to be conducted to provide detailed guidance to nursing home facilities management teams as to the best way to maintain comfortable temperatures while maintaining good energy efficiency outcomes.

It should also be noted that to ensure that occupants are thermally comfortable, not only should indoor operative temperatures be maintained within the thermal comfort range suggested, but also temperature differences between rooms with a given facility should be minimised. This outcome could have been achieved in the case study facilities by changing the way the HVAC system was controlled. The operation mode of the HVAC system (i.e. cooling, heating) and zone temperature setpoints were manually controlled by staff members using zone thermostats. However, in common areas, staff members should not have the access to thermostats since they may adjust thermal environmental conditions solely based on their personal thermal preferences. Instead, the operation mode and the zone set-points should be controlled by a centralised building management system.

\subsection{Applicability of the PMV Model}

Participants in this study were comfortable when their estimated PMV was negative. Similar results were previously obtained by Wong et al. [9] who also found that nursing home residents were thermally neutral when PMV was negative. Wong et al. estimated that the average PMV of those residents who were thermally comfortable were $-1.01,-1.04,-0.96,-.34$ and -0.24 for the following age groups $25-50,60-69,70-79,80-89$ and $\geq 90$ years, respectively. In the present study, the beta coefficient for PMV (gradient of the linear equation) was lower than 1, meaning that per unit increase in the PMV, the Personal Thermal State vote increases by 0.338 and 0.613 units for residents and nonresidents, respectively. Hence, participants were more tolerant of variations in their microclimate than that predicted by the PMV model. Yang et al. [8] also observed that the regression coefficient of the linear equation correlating PMV and Personal Thermal State was lower than $1(\mathrm{~B}=0.71)$. However, in contrast to the results of Wong et al. and of the present study, Yang et al. estimated that when PMV $=0$ the Personal Thermal State vote of their nursing home residents was 0 . 


\subsection{Limitations}

The main limitations of this present study were as follows.

- Participants were not asked to complete the questionnaire while showering or bathing. Therefore, a thermal comfort zone for bathrooms was not determined.

- The field study was conducted during daytime. Further research is needed to investigate thermal requirements of residents at night times.

\section{Conclusions}

This paper reports on an in-depth investigation into thermal perceptions, preferences and adaptive behaviours of occupants of nursing homes.

The analysis of the results showed that clothing adjustment and local air velocity control were two behavioural adjustments widely employed by participants to compensate for both cold and warm unsatisfactory thermal conditions. Residents tended to increase the insulation level of their clothes more than non-residents when compensating for changes in indoor operative temperature, $T_{\mathrm{o}}$. Furthermore, variations in total clothing insulation of participants were found to be significantly correlated to variations in operative temperature as well as to age, metabolic rate and BMI; whilst gender was not a significant predictor.

Personal cooling fans and window opening practices were almost certainly two adaptive strategies widely used by participants to compensate for warm indoor conditions as the average air velocity indoors was positively correlated with an increase in indoor operative temperature.

Results also showed that the PMV index was not a precise predictor of the Personal Thermal State of both adults and older adults. In general terms results showed that participants were most comfortable when their estimated PMV was negative. Suggesting that they were comfortable when they were located in an environment estimated to be "slightly cold" by the PMV index.

The neutral temperature for residents in summer $\left(22.9^{\circ} \mathrm{C}\right)$ was $0.9^{\circ} \mathrm{C}$ higher than for non-residents $\left(22.0^{\circ} \mathrm{C}\right)$. Moreover, residents were found to be more tolerant to temperature variations than nonresidents. For a target level of PPD $=10 \%$, the estimated comfort range for residents was found to be $19.1-26.2^{\circ} \mathrm{C}$ and for non-residents $19.8-24.2^{\circ} \mathrm{C}$. 
This study offers strong evidence that nursing homes should be designed and operated to provide appropriate indoor thermal environments that ensure occupants are not exposed to colder or hotter temperatures than those recommended, since exposing resident to hot and cold thermal conditions may not only negatively impact their comfort but also their health. Ideally, control of the thermal environment in nursing homes should be achieved through good low-energy/passive building design and operational strategies, so as to minimise greenhouse emissions resulting from the operation of mechanical ventilation, heating and cooling systems.

Staff members working in the aged care sector should be trained to provide high standards of thermal care to residents. The provision of proper thermal care should not be limited to controlling the zone temperature in each space (by either passive/natural or mechanical means); but staff should also be trained to help residents to address their thermal needs, particular for residents who may not have the ability to do this themselves. Staff should also help facilitate behavioural thermal adjustments in residents (e.g. consuming hot or cold drinks, adjusting clothing insulation throughout the day, opening and closing windows, turning cooling fans on and off), which were found to significantly improve residents' thermal comfort.

The results provided in this manuscript may assist regulatory authorities and government agencies to develop better guidelines. Guidelines will help aged care providers to understand how to best operate their buildings to deliver high standards of thermal care to their residents, and a comfortable environment that enhances the productivity of staff members. Furthermore, the present study is also relevant for thermal comfort research since it provides evidence as to how older adults perceive their thermal environment. These results may be used in future to extend the applicability of the international thermal comfort standards, which to date are not applicable to older adults. 


\section{Funding}

This work was supported by a scholarship awarded to the first author by the University of Wollongong (UOW) and aged care provider Warrigal. 


\section{References}

[1] WHO, WHO | Ageing and health, (2015).

http://www.who.int/mediacentre/factsheets/fs404/en/ (accessed March 9, 2017).

[2] WHO, World Report on Ageing and Health, World Health Organization, Geneva, 2015.

[3] A.M. Sanford, M. Orrell, D. Tolson, A.M. Abbatecola, H. Arai, J.M. Bauer, A.J. Cruz-Jentoft, B. Dong, H. Ga, A. Goel, R. Hajjar, I. Holmerova, P.R. Katz, R.T.C.M. Koopmans, Y. Rolland, R. Visvanathan, J. Woo, J.E. Morley, B. Vellas, An International Definition for "Nursing Home," J. Am. Med. Dir. Assoc. 16 (2015) 181-184. doi:10.1016/j.jamda.2014.12.013.

[4] AIHW, Residential aged care facility - Australian Institute of Health and Welfare, (2017). http://meteor.aihw.gov.au/content/index.phtml/itemId/384424 (accessed September 17, 2017).

[5] G. Walker, S. Brown, L. Neven, Thermal comfort in care homes: vulnerability, responsibility and thermal care, Build. Res. Inf. (2015) 37-41. doi:10.1080/09613218.2014.998552.

[6] F. Tartarini, P. Cooper, R. Fleming, Thermal environment and thermal sensations of occupants of nursing homes: a field study, Procedia Eng. - Int. High-Performance Built Environ. Conf. A Sustain. Built Environ. Conf. 2016 Ser. (SBE16), iHBE 2016. 180 (2017) 373-382. doi:10.1016/j.proeng.2017.04.196.

[7] J. van Hoof, M.J. Verkerk, Developing an integrated design model incorporating technology philosophy for the design of healthcare environments: A case analysis of facilities for psychogeriatric and psychiatric care in The Netherlands, Technol. Soc. 35 (2013) 1-13. doi:10.1016/j.techsoc.2012.11.002.

[8] J. Yang, I. Nam, J.R. Sohn, The influence of seasonal characteristics in elderly thermal comfort in Korea, Energy Build. 128 (2016) 583-591. doi:10.1016/j.enbuild.2016.07.037.

[9] L.T. Wong, K.N.K. Fong, K.W. Mui, W.W.Y. Wong, L.W. Lee, A Field Survey of the Expected Desirable Thermal Environment for Older People, Indoor Built Environ. 18 (2009) 336-345. doi:10.1177/1420326X09337044.

[10] J.K.W. Wong, M. Skitmore, L. Buys, K. Wang, The effects of the indoor environment of residential care homes on dementia suffers in Hong Kong: A critical incident technique approach, Build. Environ. 73 (2014) 32-39. doi:10.1016/j.buildenv.2013.12.001.

[11] J. van Hoof, J.L.M. Hensen, Thermal comfort and older adults, Gerontechnology J. 4 (2006) 223-228.

[12] J. van Hoof, H.S.M. Kort, M.S.H. Duijnstee, P.G.S. Rutten, J.L.M. Hensen, The indoor environment and the integrated design of homes for older people with dementia, Build. Environ. 45 (2010) 1244-1261. doi:10.1016/j.buildenv.2009.11.008.

[13] J. van Hoof, H.S.M. Kort, Thermal comfort and HVAC design for people with dementia, Proc. 9th Glob. Comference Aging. (2008) 1-18.

[14] J. van Hoof, H.S.M. Kort, M.S.H. Duijnstee, A.M.C. Schoutens, J.L.M. Hensen, S.H.A. Begemann, The indoor environment in relation to people with dementia, in: P. Strom-Tejsen, et al. (Eds.), Proc. 11th Int. Conf. Indoor Air Qual. Clim. Indoor Air, 2008: pp. 17-22.

[15] J. van Hoof, Forty years of Fanger's model of thermal comfort: Comfort for all?, Indoor Air. 18 (2008) 182-201. doi:10.1111/j.1600-0668.2007.00516.x.

[16] P.O. Fanger, Thermal comfort: analysis and applications in environmental engineering, New York, 1970.

[17] R.-L. Hwang, C.-P. Chen, Field study on behaviors and adaptation of elderly people and their thermal comfort requirements in residential environments., Indoor Air. 20 (2010) 235-45. doi:10.1111/j.1600-0668.2010.00649.x.

[18] S. Del Ferraro, S. Iavicoli, S. Russo, V. Molinaro, A field study on thermal comfort in an Italian hospital considering differences in gender and age, Appl. Ergon. 50 (2015) 177-184. doi:10.1016/j.apergo.2015.03.014.

[19] J. van Hoof, L. Schellen, V. Soebarto, J.K.W. Wong, J.K. Kazak, Ten questions concerning thermal comfort and ageing, Build. Environ. (2017). doi:10.1016/j.buildenv.2017.05.008.

[20] L. Brown, E. Hansnata, H.A. La, Economic cost of dementia in Australia, Alzheimer's Australia, Canberra, 2017. 
[21] ANSI, ASHRAE, 55-2013 Thermal Environmental Conditions for Human Occupancy, American Society of Heating Refrigerating and Air-Conditioning Engineers; American National Standards Institute, Atlanta, 2013.

[22] ISO, 7730 Ergonomics of the thermal environment - Analytical determination and interpretation of thermal comfort using calculation of the PMV and PPD indices and local thermal comfort criteria, International Organization for Standardization, Geneva, 2005.

[23] ISO, 28803 Ergonomics of the physical environment - Application of International Standards to people with special requirements, International Organization for Standardization, Geneva, 2012.

[24] J. van Hoof, H.S.M. Kort, J.L.M. Hensen, M.S.H. Duijnstee, P.G.S. Rutten, Thermal comfort and the integrated design of homes for older people with dementia, Build. Environ. 45 (2010) 358-370. doi:10.1016/j.buildenv.2009.06.013.

[25] R. Fleming, B. Goodenough, L.-F. Low, L. Chenoweth, H. Brodaty, The relationship between the quality of the built environment and the quality of life of people with dementia in residential care., Dementia. 15 (2016) 1-18. doi:10.1177/1471301214532460.

[26] J. Cohen-Mansfield, P. Werner, Environmental influences on agitation: An integrative summary of an observational study, Am. J. Alzheimers. Dis. Other Demen. 10 (1995) 32-39. doi: $10.1177 / 153331759501000108$.

[27] J. van Hoof, H.S.M. Kort, H. van Waarde, M.M. Blom, Environmental interventions and the design of homes for older adults with dementia: an overview., Am. J. Alzheimers. Dis. Other Demen. 25 (2010) 202-232. doi:10.1177/1533317509358885.

[28] E. Brawley, Alzheirner's disease: designing the physical environment, Am. J. Alzheimer's Care Relat. Disord. Res. (1992) 3-8.

[29] F. Tartarini, P. Cooper, R. Fleming, M. Batterham, Indoor Air Temperature and Agitation of Nursing Home Residents With Dementia, Am. J. Alzheimer's Dis. Other Dementias®. (2017). doi:10.1177/1533317517704898.

[30] ACFA, Fourth report on the Funding and Financing of the Aged Care Sector, Aged Care Financing Authority, Canberra, 2016.

[31] ASHRAE, 2009 ASHRAE Handbook: Fundamentals, American Society of Heating Refrigerating and Air-Conditioning Engineers, Atlanta, GA, 2009.

[32] ABCB, NSW and ACT Climate Zone Map, Australian Building Codes Board, 2012.

[33] M.A. Humphreys, The optimum diameter for a globe thermometer for use indoors, Build. Res. Establ. 20 (1977) 135-140.

[34] ISO, 10551 Ergonomics of the thermal environment - Assessment of the influence of the thermal environment using subjective judgement scales, International Organization for Standardization, Geneve, 1995.

[35] ISO, 7726 Ergonomics of the thermal environment: instruments for measuring physical quantities physiques, International Organization for Standardization, Geneva, 1998.

[36] WHO, Global Database on Body Mass Index, (2010). doi:papers3://publication/uuid/DF45B6E6-94B7-4B8A-9775-3A1313BA45EC.

[37] Queensland Government, Using Body Mass Index, 2014.

[38] Z. Lin, S. Deng, A study on the thermal comfort in sleeping environments in the subtropicsMeasuring the total insulation values for the bedding systems commonly used in the subtropics, Build. Environ. 43 (2008) 905-916. doi:10.1016/j.buildenv.2007.01.027.

[39] A.P. Gagge, J.A.J. Stolwijk, J.D. Hardy, Comfort and thermal sensations and associated physiological responses at various ambient temperatures, Environ. Res. 1 (1967) 1-20. doi:10.1016/0013-9351(67)90002-3.

[40] S.H. Hong, J. Gilbertson, T. Oreszczyn, G. Green, I. Ridley, A field study of thermal comfort in low-income dwellings in England before and after energy efficient refurbishment, Build. Environ. 44 (2009) 1228-1236. doi:10.1016/j.buildenv.2008.09.003.

[41] M. Indraganti, K.D. Rao, Effect of age, gender, economic group and tenure on thermal comfort: A field study in residential buildings in hot and dry climate with seasonal variations, Energy Build. 42 (2010) 273-281. doi:10.1016/j.enbuild.2009.09.003.

[42] F.E. Harrell, Ordinal logistic regression, in: Regres. Model. Strateg., 2015: p. 560. doi:10.1007/978-1-4757-3462-1. 
[43] R.-L. Hwang, T.P. Lin, M.J. Cheng, J.H. Chien, Patient thermal comfort requirement for hospital environments in Taiwan, Build. Environ. 42 (2007) 2980-2987.

doi:10.1016/j.buildenv.2006.07.035.

[44] L. Schellen, W.D. van Marken Lichtenbelt, M.G.L.C. Loomans, J. Toftum, M.H. de Wit, Differences between young adults and elderly in thermal comfort, productivity, and thermal physiology in response to a moderate temperature drift and a steady-state condition, Indoor Air. 20 (2010) 273-283. doi:10.1111/j.1600-0668.2010.00657.x.

[45] R. Fink, I. Erzen, S. Medved, D. Kastelec, Experimental research on physiological response of elderly with cardiovascular disease during heat wave period, Indoor Built Environ. 0 (2014) 110. doi:10.1177/1420326X13519348.

[46] M. Loughnan, M. Carroll, N.J. Tapper, The relationship between housing and heat wave resilience in older people, Int. J. Biometeorol. (2014) 1291-1298. doi:10.1007/s00484-0140939-9.

[47] S. Conti, M. Masocco, P. Meli, G. Minelli, E. Palummeri, R. Solimini, V. Toccaceli, M. Vichi, General and specific mortality among the elderly during the 2003 heat wave in Genoa (Italy)., Environ. Res. 103 (2007) 267-74. doi:10.1016/j.envres.2006.06.003.

[48] J.B. Worfolk, Heat Waves: Their Impact on the Health of Elders, Geriatr. Nurs. (Minneap). 21 (2000) 70-77.

[49] WHO, Housing, Energy and Thermal Comfort A review of 10 countries within the WHO European Region, World Health Organization, Geneva, 2007.

[50] E.J.W. Van Someren, Age-Related Changes in Thermoreception and Thermoregulation, in: E. Masoro, S. Austad (Eds.), Handb. Biol. Aging (Seventh Ed., Seventh Ed, Elsevier, San Diego, 2011: pp. 463-478. doi:10.1016/B978-0-12-378638-8.00022-1.

[51] WHO, UNEP, Indoor environment: health aspects of air quality, thermal environment, light and noise, World Health Organization; United Nations Environmental Programme, Geneva, 1990. 


\section{Highlights}

- Participants effectively adjusted their clothing insulation and local air velocity.

- Total clothing insulation varied as function of age, metabolic rate and BMI.

- The neutral temperature for residents in summer was higher than for non-residents.

- The estimated comfort range for residents was $19.1-26.2^{\circ} \mathrm{C}$.

- The PMV was not a precise predictor of the personal thermal state of occupants. 